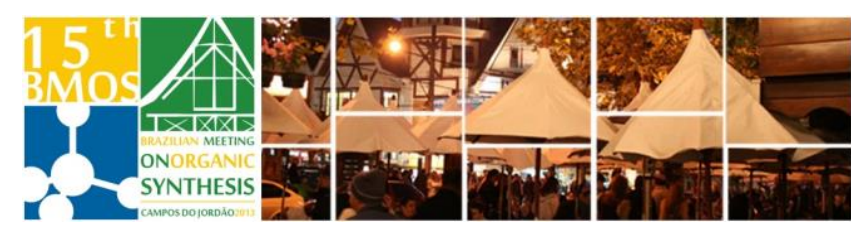

\title{
Synthetic studies for bisthiazolidine stepwise preparation
}

\author{
Valerie Castillo, Graciela Mahler* \\ Cátedra de Química Farmacéutica, DQO, Facultad de Química, Gral Flores 2124, Montevideo, Uruguay \\ *gmahler@fq.edu.uy:
}

Keywords: bisthiazolidines, MCR, thiazolidines

\section{INTRODUCTION}

Our research group is interested in the development of new synthetic methodologies for the rapid generation of chemical libraries with high molecular diversity and complexity. During the last years we have been exploring the potential of the domino cascade reactions, which are a combination of multiple transformations in a single process. Particularly Iminium ions are useful as versatile intermediates for such kind of reactions as they may serve as electrophiles in a diverse range of bond forming possibilities. Recently we generated a focused library of thiols to evaluate it bioactivity as enzyme inhibitors. We also expanded the diversity of this system and were able to generate bisthiazolidines I or bis-thiiranes II by Multicomponent Connection Reaction (MCR) using iminium ions. [1]

Figure 1. Double cyclization for the synthesis of bisthiazolidines I

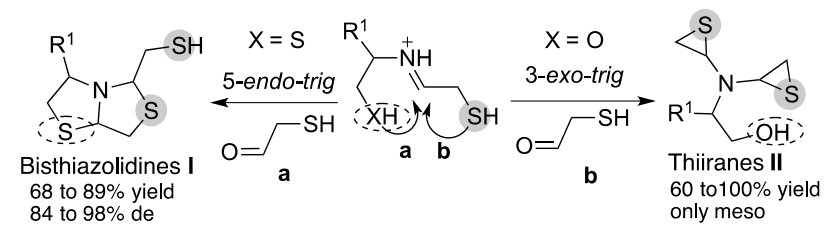

In the present work is aimed to synthesize bisthiazolidine $\mathrm{B}$, substituted with $\mathrm{H}$ or $\mathrm{CO}_{2} \mathrm{Et}$ at 2 position, and with variations at the $R^{2}$ position. To avoid double cyclization and to introduce variability at $R^{2}$ position, we proposed a step-wise procedure using the thiazolidine-1 as a key intermediate, see Figure 2.

Figure 2. Retrosynthetic analysis of bisthiazolidine B

$$
\text { 1a: } \mathrm{R}^{1}=\mathrm{H} \text {; or } 1 \mathrm{~b}: \mathrm{CO}_{2} \mathrm{Et}
$$

\section{RESULTS AND DISCUSSION}

The first attempt to control the double cyclization was by preparing protected mercaptoacetaldehyde 3, see Scheme 1.
Scheme 1. Syntehsis of trityl thiazolidine 4

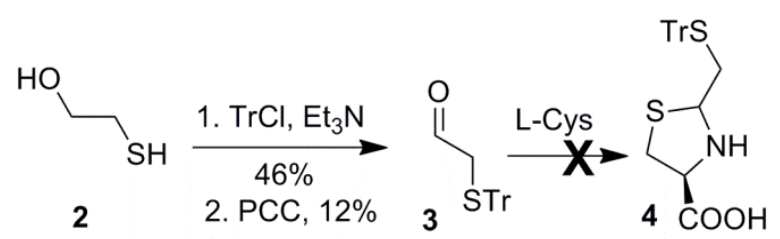

Unfortunately attempts to monocyclization to obtain the desired thiazolidine 4 failed. We obtained a complex mixture of bisthiazolidines probably by the in situ S-Tr deprotection.

We changed the thiol-protecting group by a benzyl. Condenzation with L-Cys followed by deprotection led to the desired thiazolidine 1a, but in low yield, see Scheme 2.

Scheme 2. Synthesis of thiazolidine 1a.

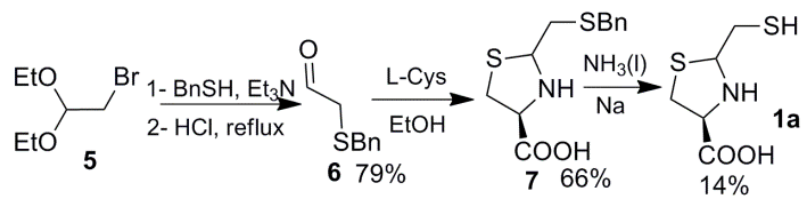

Preparation of thiazolidine $\mathbf{1 b}$ was achieved by condensation of L-Cysteine with the corresponding $\alpha$-thioketone 10, prepared according literature procedures. [2]

Scheme 3. Synthesis of thiazolidine $\mathbf{1 b}$

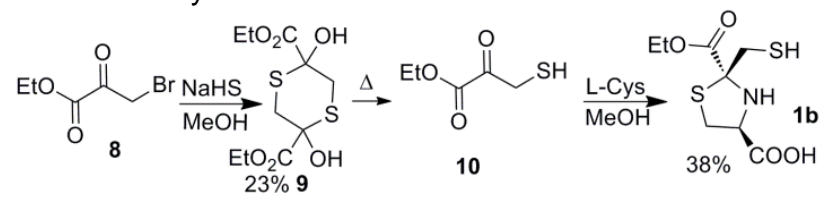

\section{CONCLUSION}

We were able to prepare thiazolidines $\mathbf{1} \mathbf{a}-\mathbf{b}$, useful building blocks for the synthesis of bisthiazolidines B. Further efforts are been carried out to prepare new bisthiazolidines derivatives.

\section{ACKNOWLEDGEMENTS}

V. Martínez and H. Pezaroglo for RMN spectra. Project CSIC 807 and CSIC-grupos.

\section{REFERENCES}

${ }^{1}$ Saiz C, Castillo V, Mahler G. Synlett 2012, 7, 1090.

${ }^{2}$ Herbert T. Nagasawa, David J. W. Goon, Daune L. Crankshaw, Robert Vince and Steven E. Patterson. J. Med. Chem. 2007, 50, 6462-4. 